\title{
Fournier's gangrene: outcome analysis and prognostic factors
}

\author{
CS Meki', TI Mangwiro ${ }^{1}, \mathrm{~J}_{\text {Lazarus }}^{2}$ \\ ${ }^{1}$ Department of Surgery, University of Zimbabwe, Harare, Zimbabwe, 2016 \\ ${ }^{2}$ Division of Urology, University of Cape Town
}

Corresponding author: ChristopherSMeki(drsciemeki@yahoo.com)

\begin{abstract}
Background: Fournier's gangrene is an infective necrotising fasciitis of the external genitalia and perineum associated with significant morbidity and mortality. The factors associated with non survival have been described but are not universally accepted. The identification of prognostic factors remains critical to improve outcomes.

Objectives: To determine the hospital based mortality and factors associated with non-survival among subjects with a clinical diagnosis of Fournier's gangrene.

Methods: A prospective hospital based observational study on 51patients with a clinical diagnosis of Fournier's gangrene over a 2-year period. A comparison was made between survivors and non-survivors to establish prognostic factors associated with non survival.

Results: The disease related hospital mortality was $27 \%(14 / 51)$. The mean age of the 51 , all male patients was 47 years. An older age was significantly associated with non-survival $(p=0.02)$. The presence of renal dysfunction $(p=0.001)$, severe sepsis $(p=0.000)$, delay in surgical debridment $(p=0.04)$, urogenital source of infection $(p=0.01)$, a body surface area involvement of greater than $5 \%(\mathrm{p}=0.006)$, abdominal wall involvement $(\mathrm{p}=0.02)$ on admission were significant factors associated with mortality. The presence of either HIV infection or diabetes mellitus was not a prognostic indicator of mortality. The clinical and biochemical parameters on admission associated with non survival were a high respiratory rate $(\mathrm{p}=0.03)$, a low hemoglobin $(\mathrm{p}=0.0001)$, an elevated blood urea nitrogen $(\mathrm{p}=0.005)$ and creatinine $(\mathrm{p}=0.01)$. Multivariate logistic regression analysis did not show any independent factors associated with non survival.

Conclusion: Fournier's gangrene remains a fatal condition with a hospital mortality of $27 \%$. Prognostic factors for non survival include an advanced age, a urogenital source of infection, abdominal involvement, severe sepsis and renal dysfunction.
\end{abstract}

S Afr J Surg 2018;56(3)

http://dx.doi.org/10.17159/2078-5151/2018/v56n3a2409

\section{Introduction}

Fournier's gangrene is a potentially fatal necrotising fasciitis involving the external genitalia, perineum and perianal regions. ${ }^{[1]}$ This disease process is commonly caused by a polymicrobial infection that results in an obliterative endarteritis of small blood vessels causing necrosis of the subcutaneous tissue and its fascial planes. The condition initially described as an idiopathic process by Sir Alfred Fournier's in 1883, commonly has an identifiable source of infection. This infective process can arise from the urogenital tract, ano-rectum or cutaneous source commonly in association with some form of underlying immunosuppression. ${ }^{[2]}$ Aggressive fluid resuscitation, early surgical debridement and broad spectrum antibiotic therapy are crucial in the management of this debilitating disease. The worldwide mortality rate has remained high with an average mortality of $20-30 \%$ despite advances in treatment over the years. ${ }^{[3]}$ The factors associated with mortality have been described but are not universally accepted. The identification of prognostic factors is vital to establish an optimal treatment strategy and help to improve outcomes. The main objective of this study was to determine the disease related mortality and the factors associated with mortality among patients with a clinical diagnosis of Fournier's gangrene in our environment.

\section{Materials and Methods}

This study was a hospital based two-year prospective observational study at three tertiary urological centres in Harare, Zimbabwe on 51 consecutive patients admitted with a clinical diagnosis of Fournier's gangrene. The study was carried out after approval by the relevant ethical institutional review board and after obtaining full written consent from the study participants. The diagnosis of Fournier's gangrene was based on history, physical examination and investigations of patients upon admission. The data on patients' demographics, 
clinical presentation, investigations and treatment were recorded on a specifically designed data collection tool. The extent of disease involvement was calculated as a percentage of total body surface area using a modified body surface area nomogram used routinely to assess the extent of burn injuries as modified by Palmer et al, in which the penis, scrotum, and perineum each account for $1 \%$ of the body surface area while each ischio-rectal fossa accounts for $2.5 \% .{ }^{[4]}$ All the patients received intravenous fluid resuscitation, immediate surgical debridement and broad spectrum intravenous antibiotics. The antibiotic regimen would then be changed according to the microbial culture and sensitivity report. Surgical debridement was repeated according to the progression of the soft tissue necrosis. The wounds were periodically inspected, dressed with glycerol and ichthammol after daily salt sits baths in addition to hydrogen peroxide chemical debridement and saline wound irrigation. Mortality was defined as disease related death during hospital stay. The data was analysed using SSPS version 13.0 to establish differences between survivors and non-survivors using the Chi squared or Fisher exact test for categorical variables. A 2 -sided tailed student $t$-test was used to compare the difference of the means between survivors and non-survivors. Multivariate logistic regression analysis was performed to determine independent variables associated with mortality.

\section{Results}

The total number of patients in this two-year study period was 51 with a mortality of $27 \%(14 / 51)$. All the study patients were male with a mean age of $47 \pm 18.3$ years.

The median duration of symptoms of the disease on presentation was 6 days. The median duration of hospital stay was 15 days with a range of 3 - 90 days. The majority of the infection originated from the urogenital tract $40 \%(22 / 51)$ while an anorectal source accounted for 32\% (15/51) and a skin source, $24 \%(12 / 51)$ of the cases. The source of infection could not be ascertained in two cases. They were two patients that developed Fournier's gangrene after adult voluntary medical male circumcision. At least 37/51 (73\%) patients had an underlying form of immunosuppression with human immunodeficiency virus (HIV) infection accounting for $36 \%$ $(18 / 51)$ of the cases while diabetes mellitus was present in only $10 \%(5 / 51)$. The mean CD4 count of patients with HIV infection was 189 cells $/ u \mathrm{~L}$, (median 191 cells $/ u \mathrm{~L}$ ) with a range of $16-389$ cells $/ u \mathrm{~L}$. They were only $5 / 18(28 \%)$ of the patients with HIV on highly active antiretroviral therapy.

\section{Prognostic factors for mortality}

The patients that did not survive were significantly older (mean, SD $58.36 \pm 21.04$ years) compared to the survivors (mean, SD $42.76 \pm 14.40$ years $)(p=0.02)$ in this series. A urogenital source of infection was significantly associated with mortality $(\mathrm{p}=0.01)$ while the anorectal source of infection was not significantly associated with mortality $(p=0.57)$ The cutaneous source of infection was significantly associated with a better outcome $(\mathrm{p}=0.003)$. The presence of HIV infection $(p=0.29)$ and diabetes mellitus $(p=0.61)$ were not significant factors for mortality. The mean CD4 count of survivors was not significantly different from non survivors, $212+$ 104 cells $/ u \mathrm{~L}$ and $154+139$ cells $/ u \mathrm{~L}$ respectively $(\mathrm{p}=0.40)$. The presence of renal dysfunction was significantly associated with mortality $(\mathrm{p}=0.001)$ with death among $7 / 10$ (70\%) patients being observed. The presence of severe sepsis on admission was significantly associated with mortality $(\mathrm{p}=0.000)$.

The following table 1 shows the results of univariate analysis of qualitative variables, comparing survivors and non survivors.

The extent of disease beyond the pelvis to involve the abdominal wall surface and a body surface area of $>5 \%$ were associated with a high mortality $(p=0.02 \& p=0.03$

Table 1: Univariate analysis of qualitative variables on admission $(\mathrm{N}=51)$

\begin{tabular}{|c|c|c|c|c|c|}
\hline \multirow{2}{*}{ Categorical Variables } & \multicolumn{2}{|c|}{ Non Survivors $(n=14)$} & \multicolumn{2}{|c|}{ Survivors $(\mathrm{n}=\mathbf{3 7})$} & \multirow[b]{2}{*}{ Pvalue } \\
\hline & Yes & No & Yes & No & \\
\hline Diabetes Mellitus & $1(20 \%)$ & $13(28 \%)$ & $4(80 \%)$ & $33(72 \%)$ & $0.69^{\S}$ \\
\hline HIV infection & $6(33 \%)$ & $8(24 \%)$ & $12(67 \%)$ & $25(76 \%)$ & 0.49 \\
\hline Renal Dysfunction & $7(70 \%)$ & $7(17 \%)$ & $3(30 \%)$ & $34(83 \%)$ & 0.001 \\
\hline Severe sepsis & $10(83 \%)$ & $4(10 \%)$ & $2(17 \%)$ & $35(90 \%)$ & 0.000 \\
\hline Urogenital infection & $10(45 \%)$ & $4(14 \%)$ & $12(55 \%)$ & $25(68 \%)$ & 0.01 \\
\hline Cutaneous infection & $0(0 \%)$ & $14(39 \%)$ & $15(100 \%)$ & $22(61 \%)$ & $0.003^{\S}$ \\
\hline Anorectal source & $3(25 \%)$ & $11(28 \%)$ & $9(75 \%)$ & $28(72 \%)$ & $0.57^{\S}$ \\
\hline Debridement after $24 \mathrm{hrs}$ of admission & $5(62 \%)$ & $8(19 \%)$ & $3(38 \%)$ & $34(81 \%)$ & 0.01 \\
\hline$\pm \mathrm{TBSA}>5 \%$ & $7(58 \%)$ & $7(18 \%)$ & $5(42 \%)$ & $32(82 \%)$ & 0.006 \\
\hline Abdominal involvement & $4(80 \%)$ & $10(21 \%)$ & $1(20 \%)$ & $36(78 \%)$ & $0.02^{\S}$ \\
\hline \multicolumn{6}{|l|}{$\begin{array}{l}* \text { p value significant level }<0.05 \\
\pm \text { TBSA - Total body surface area involved } \\
\S \text { Fischer exact test }\end{array}$} \\
\hline
\end{tabular}


Table 2: Univariate analysis of quantitative variable on admission. ( $\mathrm{N}=51$ )

\begin{tabular}{|c|c|c|c|}
\hline Variable & $\begin{array}{l}\text { Non-survivors }(n=14) \\
(\text { mean } \pm \text { SD) }\end{array}$ & $\begin{array}{c}\text { Survivors }(n=37) \\
(\text { mean } \pm \text { SD })\end{array}$ & P value* \\
\hline Age (years) & $58.36 \pm 21.04$ & $42.76+14.40$ & 0.02 \\
\hline Duration of Symptoms (days) & $8.69 \pm 5.23$ & $6.86+5.13$ & 0.27 \\
\hline${ }^{\wedge} \operatorname{TBSA}(\%)$ & $5.29 \pm 3.14$ & $2.34+1.81$ & 0.004 \\
\hline Number surgical debridement & $2.23 \pm 1.30$ & $2.72+1.69$ & 0.28 \\
\hline Respiratory rate (breaths/minute) & $24.85+6.20$ & $20.81+2.15$ & 0.03 \\
\hline Heart rate (beats per min) & $103.46+14.48$ & $99.41+19.82$ & 0.43 \\
\hline White cell count $\left(\mathrm{x} 10^{12} / \mathrm{L}\right)$ & $23.17+19.75$ & $13.10+6.79$ & 0.08 \\
\hline Hemoglobin (g/dL) & $7.84+2.35$ & $11.50+2.76$ & 0.0001 \\
\hline Platelet count $(\mathrm{x} \mathrm{10} / \mathrm{L})$ & $220+205.64$ & $298+173.27$ & 0.22 \\
\hline Sodium $(\mathrm{mmol} / \mathrm{L})$ & $134.42+5.88$ & $136.11+4.95$ & 0.35 \\
\hline Potassium (mmol/L) & $5.11+1.72$ & $4.21+0.73$ & 0.08 \\
\hline Urea $(\mathrm{mmol} / \mathrm{L})$ & $38.52+33.14$ & $8.32+5.69$ & 0.005 \\
\hline Creatinine $(u \mathrm{~mol} / \mathrm{L})$ & $544.83+515.23$ & $136.48+100$ & 0.01 \\
\hline Random Blood sugar (mmol/L) & $6.87+2.93$ & $8.51+6.42$ & 0.22 \\
\hline
\end{tabular}

respectively). A time to first surgical debridement, beyond 24 hours from admission was a significant factor associated with mortality $(p=0.04)$, although the number of surgical debridements did not differ significantly between survivors and non-survivors $(\mathrm{p}=0.28)$.

The admitting clinical and biochemical parameters found to be significantly associated with non-survival on univariate analysis were an increased respiratory rate $(\mathrm{p}=0.04)$, a low haemoglobin $(p=0.0001)$, an elevated blood urea nitrogen $(p=0.005)$ and creatinine levels $(p=0.02)$.

Multivariate logistic regression analysis did not show any of the above factors to be independently associated with mortality.

\section{Discussion}

The mortality due to Fournier's gangrene varies worldwide with a range from $3 \%$ to $45 \% .{ }^{[3]}$ The mortality rates have remained high despite advancement in medical care and availability of intensive care and monitoring. In this prospective study of 51 patients, the hospital based mortality among patients admitted with a clinical diagnosis of Fournier's gangrene was found to be $27 \%$. A recent report from North America reports a lower mortality of $11.1 \%{ }^{\left[{ }^{[}\right]}$ The mortality from studies done in other African countries range from $3.6 \%$ to $24 \% .^{[7,8,9]}$ A recent 3 year review study on 20 patients from Saudi Arabia recorded zero mortality. ${ }^{[10]}$ They attributed the good prognosis to the moderate severity of their cases and aggressive radical surgical debridement. This resulted in significant morbidity with $15 \%$ having a penile amputation and $30 \%$ of their patients an orchiectomy. ${ }^{[10]}$ This demonstrate the heterogeneity of cases of Fournier's gangrene across the different national populations. The lack of easy access and availability of critical care support for patients with severe sepsis may explain the rather still higher mortality among our series of a developing country.

In our series, the mean age of the patients was 47 years which is consistent with most studies from African countries like Nigeria, Kenya and Zambia where the patient average age is between 36 years and 48 years..$^{[3,8,11]}$ The patients in our series are younger compared to those from studies of Europe and North America were the mean age of the patients ranges from 55.8 to 63.5 years. ${ }^{[10,12,13]}$ In this study we noted that patients that did not survive were significantly older than those that survived $(\mathrm{p}=0.02)$. In a population based study by Sorensen et al, an older age was strong predictor of mortality (OR 4-15, $\mathrm{P}<0.0001) .{ }^{[13]}$ However a study by Tuncel et al did not find any significant age difference between survivors and non-survivors. ${ }^{[5]}$

The ano-rectal source of infection has been associated with non-survival due to its source of diverse and virulent population of enteric pathogenic bacteria. ${ }^{[15]}$ However in this study the urogenital source of infection instead was significantly associated with a higher mortality $(\mathrm{p}=0.01)$. Interestingly $57 \%$ of the patients with a urogenital source of infection had renal dysfunction at presentation mostly associated with chronic urinary obstruction. Renal dysfunction in the presence of sepsis has a significant bearing on outcomes as evidenced from this study $(\mathrm{p}=0.001)$. A cutaneous source of infection has the least mortality as seen in other studies. ${ }^{[8]}$ This low mortality has been attributed to the low virulence of skin commensals.

Diabetes mellitus has been described as the commonest underlying risk factor to the development of Fournier's 
gangrene, accounting for up to $60 \%$ of the cases from the western literature. ${ }^{[1,2,13]}$ This is in stark contrast to our study in which HIV infection is the commonest underlying risk factor $(36 \%)$ while diabetes mellitus only accounts for $10 \%$ of the cases. In similar study to ours HIV infection has overtaken diabetes mellitus (16\% vs $11 \%$ ) as the commonest underlying risk factor. ${ }^{[9]}$ The HIV epidemic potentially opens a huge population at risk of developing Fournier's gangrene in sub Saharan Africa. The presence of HIV infection is not a significant factor associated with non-survival similar to findings by Elem and colleagues. ${ }^{[11]}$ The presence of diabetes mellitus is not significantly associated with mortality in our environment similar to findings of a previous study. ${ }^{[16]}$

In this study a body surface area involvement of greater than $5 \%$ and extension of disease beyond the pelvis to involve the abdominal wall, are significant factors associated with mortality. They are previous studies to support the finding that these patients have a higher mortality though survival is not directly proportional to body surface area involved. ${ }^{[4,17]}$ Yilmazalar et al in their report added a dissemination score to include pelvic and abdominal extension of disease to form a modified Fournier's gangrene severity index (FGSI) score. ${ }^{[17]}$

The abnormal biochemical parameters found in patients with Fournier's gangrene may potentially predict mortality. ${ }^{[5,12,14,17]}$ Laor et al noted that biochemical parameters taken individually do not appear to have any practical clinical application. They created the Fournier's gangrene severity index (FGSI) score which is based on the deviation of these parameters from the normal. ${ }^{[12]}$ However its use in clinical practice has largely remained in the area of research despite its use being validated in many studies. ${ }^{[5,16]}$ Similarly to their study, a low haemoglobin, an elevated blood urea and creatinine are strongly associated with non-survival.

The time to first surgical debridement should be kept to a minimum as a delay beyond 24 hours is significantly associated with mortality $(\mathrm{p}=0.006) .{ }^{[5]}$ The number of surgical debridement done on a patient with Fournier's gangrene does not seem to be associated with non-survival in this study. Multiple debridement even if performed in the first 24 hours of admission has been noted not to be associated with increased mortality. ${ }^{[4]}$

Multivariate regression analysis performed in our study did not show any independent factors to be associated with mortality which could be attributed to the smaller number of cases recorded in our study. It remains necessary for multiinstitutional prospective studies to accrue enough patients necessary to further validate the prognostic factors of this debilitating condition.

Fournier's gangrene remains a highly lethal disease. The factors associated with mortality are an older age, a genitourinary source of infection, presence of renal dysfunction on admission, a body surface area involvement of greater than 5\%, abdominal involvement, severe sepsis and delay in surgical debridement. HIV infection, diabetes mellitus, and delay in presentation as well as the number of surgical debridement do not seem to affect mortality. The identification of prognostic factors potentially helps in coming up with strategies that improve outcomes in these patients.

\section{Financial disclosure - none}

\section{REFERENCES}

1. Smith GL, Bunker CB, Dineen MD. Fournier's gangrene. Br J Urol 1998; 81:347-55,

2. Morpurgo E, Galandiuk S. Fournier's gangrene. Surg Clin N Am 2002; 82:1213-24. http://dx.doi.org/10.1016/S00396109(02)00058-0

3. Eke N. Fournier's gangrene: A review of 1726 cases. Br J Surg 2000; 87:718-28. http://dx.doi. org/10.1046 j.1365-2168.2000.01497. x.

4. Palmer LS, Winter HI, Tolia BM, et al. The limited impact of involved surface area and surgical debridement on survival in Fournier's gangrene. Br J Urol 1995;76(2):208-12.

5. Tuncel A, Aydin O, Tekdogan U, et al. Fournier's gangrene: Three years of experience with 20 patients and validity of the Fournier's Gangrene Severity Index Score. Eur Urol 2006;50:838-43. http://dx.doi.org/10.1016/j.eururo.2006.01.030

6. Tang et al. The evaluation of microbiology and prognosis of Fournier's gangrene in the past five years. Springer plus 2014;4:14

7. Aliyu S, Ibhrahim G, Ali N, Waziri AM. Fournier's gangrene as seen at the University of Maiduguri Teaching Hospital. ISRN Urology 2013;673121

8. Okeke LI, Fournier's gangrene in Ibdan.Afr J Med Sci, (2000);29:323

9. Ngugi $P$, Magoha G, Nyaga $P$ et al, Fournier's gangrene in the HIV era. African health Sciences, 2014; 14 (4):1063-1068. doi:10.4314/ahs.v14i4.38

10. Katib A Al-Adawi M, Dakkak B et al. A three-year review of the management of Fournier's gangrene presented in a single Saudi Arabian institute. Central European Journal of Urology 2013;66(3):331-334. doi:10.5173/ceju.2013.03.art22

11. Elem B, Ranjan P. Impact of immunodeficiency virus (HIV) on Fournier's gangrene: observations in Zambia. Ann R Coll Surg Engl 1995;77(4):283-6.

12. Laor E, Palmer TS, Tolia BM, et al. Outcome prediction in patients with Fournier's is ipigangrene. J Urol 1995;154:89-92. http://dx.doi.org/10.1016/S0022-5347(01)67236-7

13. Sorensen MD, Krieger JN, Rivara FP, et al. Fournier's gangrene: Population based epidemiology and outcomes. J Urol 2009;181:2120-6. http://dx.doi.org/10.1016/j.juro.2009.01.034.s

14. Erol B, Tuncel A, Hanci V, et al. Fournier's gangrene: Overview of prognostic factors and definition of new prognostic parameter. Urology 2010;75:1193-8. http://dx.doi.org/10.1016/j. urology.2009.08.090.

15. Jeong HJ, Park SC, Seo IY, Rim JS. Prognostic factors in Fournier gangrene. Int J Urol 2005;12:1041 - 4. doi:10.1111/ j.1442-2042.2005.01204.x

16. Marco S L, Budia A, Di Capua C et al. Evaluation of a severity score to predict prognosis of Fournier's gangrene; BJU International, 2009;106:373-376 doi:10.1111/j.1464410X.2009.09075.x

17. Yilmazlar T, Ozturk E, Ozguc H, et al. Fournier's gangrene: An analysis of 80 patients and a novel scoring system. Tech Coloproctol 2010;14:217-23. http://dx.doi.org/10.1007/s10151010-0592-1. 